\title{
APPROACHING MEASLES AND RUBELLA ELIMINATION IN THE EUROPEAN REgION - NEED TO SUSTAIN THE GAINS
}

\author{
R Martin (RMA@euro.who.int)1, S Deshevoi1, N Buddha1, D Jankovic1 \\ 1. Communicable Diseases Unit, World Health Organization (WHO) Regional Office for Europe, Copenhagen, Denmark
}

This article was published on 17 December 2009.

Citation style for this article: Martin R, Deshevoi S, Buddha N, Jankovic D. Approaching measles and rubella elimination in the European Region - need to sustain the gains . Euro Surveill. 2009;14(50):pii=19449. Available online: http://www.eurosurveillance.org/ViewArticle.aspx?ArticleId=19449

While there is considerable focus in the World Health Organization (WHO) European Region on the introduction of new vaccines and promotion of underutilized vaccines, there are increasing challenges in sustaining the gains made with existing vaccines, where the estimated vaccine coverage rate for measles is $94 \%$ in the Region [1]. Analyses reveal that most children are not immunised on time according to national immunisation schedules and that there are pockets of low immunisation coverage at regional or local levels in the countries. These two factors set the stage for outbreaks of vaccine-preventable diseases, such as were seen with measles in the western part of the European Region [2].

In 2002, the WHO Regional Committee for Europe adopted a resolution to eliminate indigenous measles and rubella in the 53 Member States in the Region by 2010 . Elimination is defined as a situation in which sustained virus transmission cannot occur and secondary spread from importation of disease will end naturally without intervention. Key strategies to achieve this goal are: achieving and sustaining high coverage ( $\geq 95 \%)$ with two doses of measles and at least one dose of rubella vaccine through high-quality routine immunisation services; providing a second opportunity for measles immunisation through supplemental immunisation activities (SIA) in susceptible populations; using the opportunity provided by measles SIA to target populations susceptible to rubella with combined measles and rubellacontaining vaccine; and strengthening measles, rubella, and congenital rubella syndrome (CRS) surveillance through rigorous case investigation and laboratory confirmation of all suspected cases [3]. The regional strategy encourages rubella vaccination opportunities, including supplementary immunisation activities, for all rubella-susceptible children, adolescents and women of child-bearing age. All national SIA conducted in the eastern part of the WHO European Region have included rubella vaccine. In addition, rubella vaccination is part of the routine immunisation schedule all member states.

Since 1998, measles incidence in the WHO European Region has declined from 110 cases per $1,000,000$ population to historically low levels of $\leq 10$ cases per 1,000,000 in 2007 and 2008. In 2008, 29 member states reported a measles incidence of less than one per 1,000,000 population, selected as one of the indicators for monitoring progress towards elimination. This progress is based on high immunisation coverage achieved through a routine two-dose schedule for measles-containing vaccine and SIA to reach susceptible populations. The estimated regional coverage for the first dose of measles vaccine increased from 88\% in 1998 to $94 \%$ in 2008 . Moreover, reported coverage for the second dose ranged from $62 \%$ to $99 \%$ in 2008. From 2000 to 2008 , at least 17 countries conducted nationwide SIA, reaching approximately 54 million people. Surveillance has been strengthened by improving case investigation procedures, expanding case-based reporting and increasing laboratory testing.

In this issue of Eurosurveillance, articles by Richard et al. and Marinova et al. show that outbreaks in the Region are occurring primarily among children aged five to 14 years who have not been immunised or who have received only one dose of measles vaccine $[4,5]$.

While measles incidence in the Region has declined to low levels, there has been a resurgence of measles cases in western European countries owing to suboptimal coverage of measles vaccine leading to pockets of susceptible people (Figure 1 ). In $2008,92 \%$ of reported measles cases ( $n=8,264$ ) occurred in western European countries, primarily Austria, France, Germany, Italy, Spain, Switzerland and the United Kingdom. The majority of cases were not immunised (82.2\%) [6]. This is contrasts with the situation from 2004 to 2006, when more measles epidemics occurred in the eastern part of the Region, with six of the newly independent states of the former Sowjet Union accounting for $75 \%$ of reported cases [6] (Figure 2).

With the decline in the number of measles cases, many national immunisation programmes in the Region are challenged by a combination of beliefs that lead to questioning the value of immunisation and the health threat posed by measles, and result in parents' hesitancy to vaccinate children.

The two articles in this edition of Eurosurveillance clearly show that measles can be a serious health threat and lead to complications (40.5\% in Bulgaria) and hospitalisation (15\% in Switzerland and $69.7 \%$ in Bulgaria; important to note that percentage hospitalised can be affected by national policies on treatment). Furthermore, Richards et al. report one measles-related death in a previously healthy child. In addition, deaths have been reported from France and the Netherlands in 2009 [10]. Genotyping data from both countries revealed that measles are exported to other countries in the European Region. Immunisation should be seen as a social responsibility in the European Region [11]. As demonstrated in this issue for Switzerland, the ongoing transmission in western Europe has in several cases led to exportation of measles to other WHO regions, including the Region of the Americas, where the disease 
was eliminated in 2002 [4,7,9]. The cost to society and health care systems of investigating and controlling measles outbreaks needs to be further analysed. The results should be used for high-level advocacy and to ensure political commitment from governments.

In addition to measles outbreaks, large, sustained mumps outbreaks have been reported in the Region. Stein-Zamir et al. report in this issue on a mumps outbreak in religious academies in Jerusalem with a high number of cases in fully vaccinated people [12]. While it is unclear how vaccination coverage was ascertained, the finding that outbreaks occur in individuals who have received two doses of mumps vaccine has been also reported in other countries, especially in universities, the military and other closed settings, such as in Ireland, Luxembourg, the Republic of Moldova, the former Yugoslav Republic of Macedonia and the United Kingdom $[13,14,15,16,17,18]$. Vaccine failure, waning immunity and programmatic documentation of vaccine histories have been given as explanations for these outbreaks and further studies are needed to understand and document the causes.

As the WHO European Region approaches measles and rubella elimination, there is a need to better monitor progress. The three agreed criteria for this purpose are disease incidence, quality surveillance and immunity profile. Surveillance needs to be strengthened through advocacy with member states and adoption of the recently revised WHO regional surveillance guidelines, which have been adapted to address lower measles incidence levels and to emphasize the importance of laboratory confirmation, case-based reporting and the use of standardised performance indicators [19]. In October 2009, a group of international experts from all continents met in Geneva to assess the current standardised surveillance performance indicators and the indicators for monitoring progress towards measles elimination. Interruption of indigenous measles transmission for 36 months is considered one of the criteria for

\section{F I G U R E}

Coverage of measles containing vaccine (first and second dose), WHO European Region, 2008

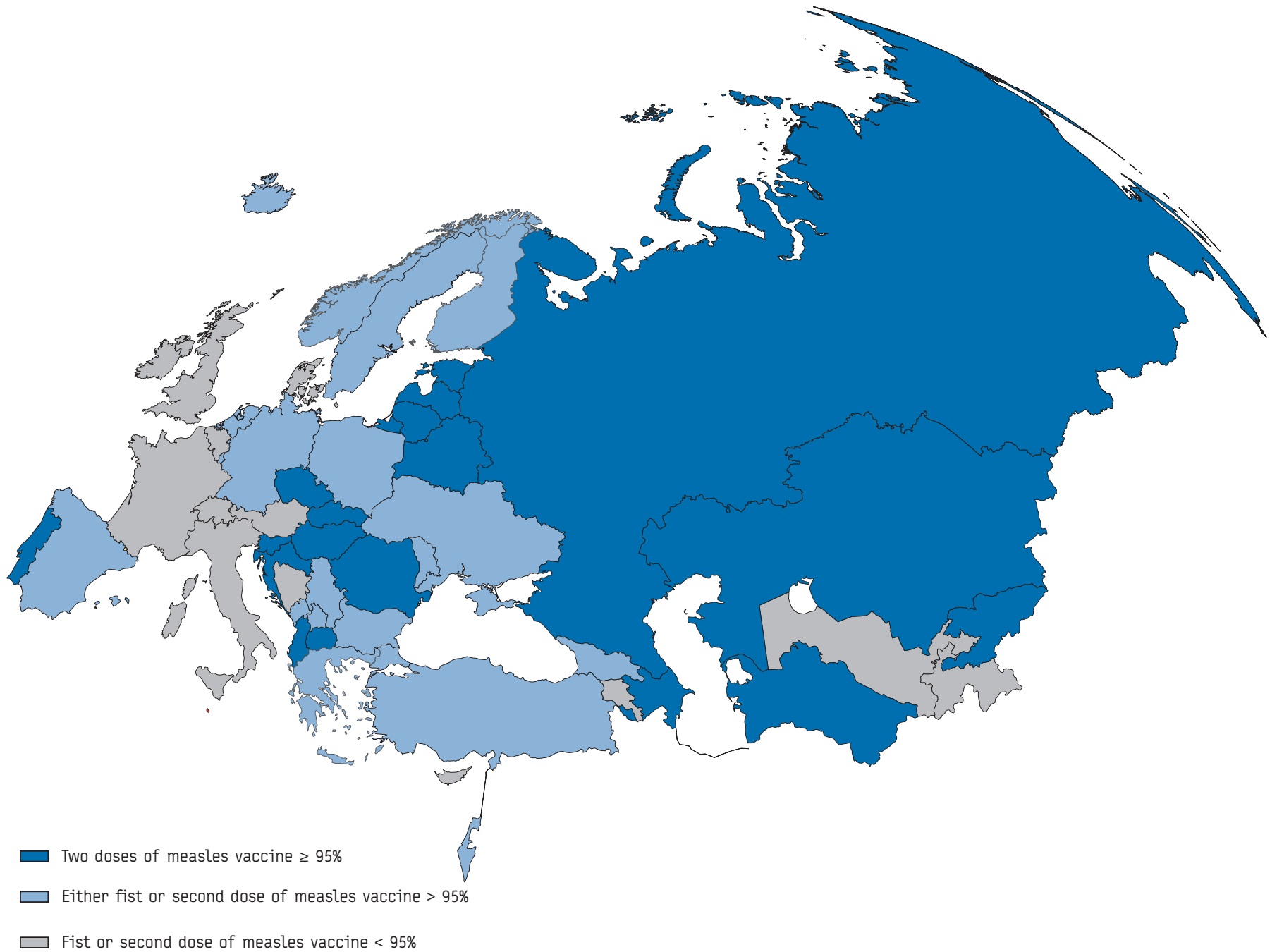

Note: The designations employed and the presentation of this material do not imply the expression of any opinion whatsoever on the part of the decretariat of the World Health Organization concerning the legal status of any country, territory, city or area or of its authorities, or concerning the

Source: World Health Organization Regional Office Europe, 2009 
elimination. Follow-up is needed at the global level to finalise the modifications based on the findings from WHO regions.

Kelly et al. from Australia report that many industrialised countries will not be able to meet the targets for the indicators, especially for the surveillance indicators. The annual process of certification of the European Region's polio-free status shows that many countries do not meet the targets for the surveillance performance indicators and not all countries conduct acute flaccid paralysis (AFP) surveillance. The national and regional certification commissions have therefore validated countries' documentation of polio-free status using other indicators related to their health systems, including the ability of the country to detect a wild poliovirus. For verifying measles and rubella elimination in member states, it is expected that once national and regional commissions for verifying elimination are formed, they will evaluate the available evidence with regard to the quality of the surveillance system of a country, with the indicators of incidence and immunity in order to verify if a country has eliminated measles and rubella. Similar criteria will also be used to document and verify elimination of rubella. As described by Aytac et al. [20], serosurveys are useful in determining rates of seropositivity but interpretation and generalisability of results should be carefully evaluated prior to developing immunisation policy in a country.

With 2010, the deadline for measles and rubella elimination, approaching, the WHO European Region faces serious threats to sustain the gains made and to reach the goal. The ongoing monitoring of performance measure indicators, disease incidence and coverage should be continued to guide the programme and verify that elimination has been achieved. To achieve elimination, enabling factors, including resources and societal support, will need to be strengthened while barriers to immunisation need to be removed. To this effect, high-level political and societal commitments are required to increase and sustain high level coverage (>95\%) with two doses of measles vaccine in children. Improving immunisation coverage to $\geq 95 \%$ must be of primary importance to prevent transmission especially among hard-to-reach populations, which include cultural or ethnic minority groups, nomadic groups, and populations that are experiencing civil unrest and/or political instability, are geographically isolated or refusing vaccination owing to religious or philosophical beliefs.

The WHO Regional Office for Europe is working with member states to identify and target populations at risk and health care professionals to communicate the need for immunisation, as well as to trace children who have not received two doses of vaccine. The annual European Immunization Week held each April provides an opportunity for member states to tailor their messages actively to communicate the benefits and risks of immunisation and strongly advocate the protection of children with political leaders, health care professionals and the general population [7].

\section{F I G U R E 2}

Reported measles cases, WHO European Region, 2004-2009

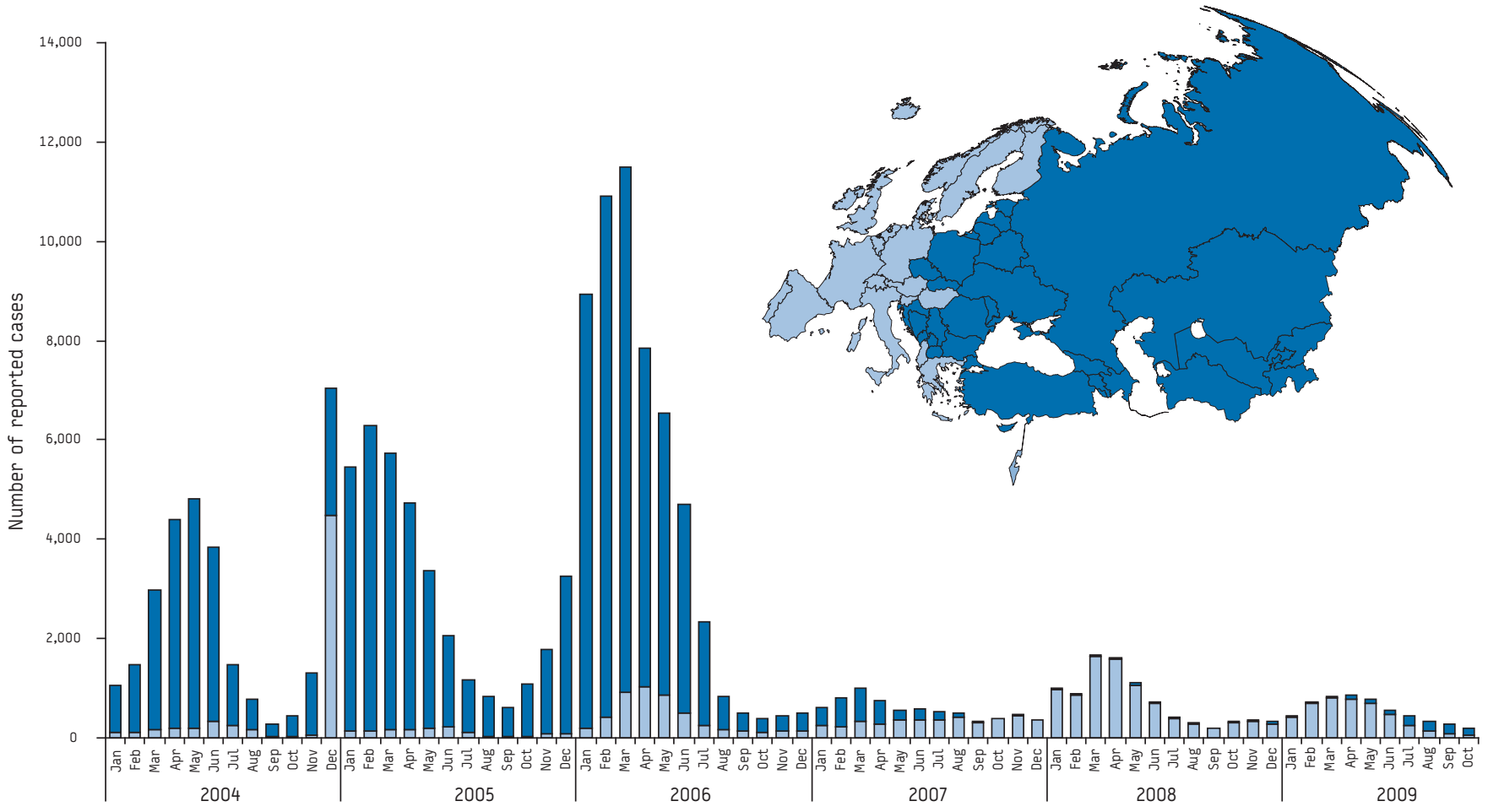




\section{References}

1. World Health Organization Regional Office for Europe. Measles immunization coverage in the WHO European Region. EURO Immunization Monitor 2009, 4:1-9. Available from: http;//www.euro.who.int/document/CPE/Euro_Immun_Mon_ Feb_2009.pdf

2. Muscat M, Bang H, Wohlfahrt J, Glismann S, Molbak K; EUVAC.NET Group. Measles in Europe: an epidemiological assessment. Lancet. 2009;373(9661):383-89.

3. WHO Regional Office for Europe. Strategic plan for measles and congenital rubella infection in the WHO European Region. Copenhagen, WHO Regional Office for Europe, 2003. Available from: http://www.euro.who.int/document/ e81567.pdf

4. Richard JL, Masserey Spicher V. Large measles epidemic in Switzerland from 2006 to 2009: consequences for the elimination of measles in Europe. Euro Surveill. 2009;14(50):pij=19443. Available online: http://www.eurosurveillance. org/ViewArticle.aspx?ArticleId=19443

5. Marinova L, Muscat M. Mihneva Z, Kojouharova M. An update on an ongoing measles outbreak in Bulgaria, April-November 2009. Euro Surveill. 2009;14(50):pii=19442. Available online: http://www.eurosurveillance.org/ ViewArticle.aspx?ArticleId $=19442$

6. Martin R, Deshevoi S, Jankovic D, Goel A, Mercer D, Laurent E et al. Progress Towards Measles Elimination - European Region 2005 - 2008. MMWR. 2009;58(06):142-145.

7. Martin R, Nørgaard O, Lazarus JV. European Immunization Week goes viral. Euro Surveill. 2009;14(16):pii=19180. Available from: http://www.eurosurveillance. org/ViewArticle.aspx?ArticleId $=19180$

8. Anonymous. Germany scores own goal on measles. Lancet Infect Dis. 2006;6(7):383.

9. Dabbagh A. Assessing the feasibility of measles eradication. WHO Study on global AGEing and adult health (SAGE). Geneva, Switzerland October 2009. Available from: http://www.who.int/entity/immunization/sage/Feasibility measles_eradication_SAGE_0ct09_DABBAGH.pdf [accessed on 15 December 2009]

10. Centralized information system for infectious diseases (CISID) [database on the Internet]. Copenhagen: World Health Organization regional Office for Europe. 2009. Available from: http://data.euro.who.int/cisid/?TabID=226538 [accessed 15 December 2009]

11. Kraemer JR, Muller CP. Measles in Europe - There is room for improvement Lancet. 2009;373(9661):356-8. DOI:10.1016/S0140-6736(08) 61850-4

12. Stein-Zamir C, Shoob H, Abramson N, Tallen-Gozani E, Sokolov I, Zentne G. Mumps outbreak in Jerusalem affecting mainly male adolescents. Euro Surveill. 2009;14(50):pii=19440. Available online: http://www.eurosurveillance. org/ViewArticle. aspx?ArticleId $=19440$

13. Health Protection Surveillance Centre. Mumps outbreak escalates. Disease surveillance report of HPSC, Ireland: Epi-Insight. 2009;10(4):1,4. Available from: http://www.ndsc.ie/hpsc/EPI-Insight/Volume102009/File,3543,en.pdf

14. Gee S, O'Flanagan D, Fitzgerald M, Cotter S. Mumps in Ireland, 2004-2008. Euro Surveill. 2008;13(18):pij=18857. Available from: http://www.eurosurveillance. org/ViewArticle.aspx?ArticleId $=18857$

15. Mossong J, Bonert C, Weicherding P, Opp M, Reichert P, Even J, Schneider F. Mumps outbreak among the military in Luxembourg in 2008: epidemiology and evaluation of control measures . Euro Surveill. 2009:14(7):pij=19121. Available from: http://www.eurosurveillance.org/ViewArticle.aspx?ArticleId=19121

16. Karagiannis I, van Lier $A$, van Binnendijk R, Ruijs $H$, Ruijs $H$, Fanoy $E$, Conyn-Van Spaendonck MA, de Melker H, Hahné S. Mumps in a community with low vaccination coverage in the Netherlands. Euro Surveill. 2008;13(24):pii=18901. Available from: http://www.eurosurveillance.org/ ViewArticle.aspx?ArticleId $=18901$

17. Bernard H, Schwarz NG, Melnic A, Bucov V, Caterinciuc N,Pebody RG, Mulders M, Aidyralieva C, Hahné S. Mumps outbreak ongoing since October 2007 in the Republic of Moldova. Euro Surveill. 2008;13(13):pii=8079. Available from: http:// www.eurosurveillance.org/ViewArticle.aspx?ArticleId $=8079$

18. Savage E, White JM, Brown DEW, Ramsay ME. Mumps Epidemic --- United Kingdom, 2004-2005; MMWR, 2006;55(07);173-175. Available from http://www. cdc.gov/mmwr/preview/mmwrhtml/mm5507a1.htm

19. World Health Organization Regional Office for Europe. Surveillance guidelines for measles, rubella and congenital rubella syndrome in the WHO European Region. Copenhagen, World Health Organization Regional Office for Europe. 2009. Available from: http://www.euro.who.int/document/E93035.pdf

20. Aytac N, Yucel AB, Yapicioglu H, Kibar F, Karaomerlioglu O, Akbaba M. Rubella seroprevalence in children in Dogankent, a rural area of Adana province in Turkey, January-February 2005. Euro Surveill. 2009;14(50):pij=19444. Available online: http://www.eurosurveillance.org/ViewArticle.aspx?ArticleId=19444 